УДК 913(470.63)

Зольникова Ю.Ф. Северо-Кавказский федеральный университет, г. Ставрополь, Россия zolnst@mail.ru

\title{
ИЗУЧЕНИЕ КЛИМАТА КАВКАЗСКИХ МИНЕРАЛЬНЫХ ВОД КАК РЕКРЕАЦИОННОГО РЕСУРСА В КОНЦЕ XIX - НАЧАЛЕ XX ВЕКА
}

Введение:

Кавказские Минеральные Воды (КМВ) - один из старейших курортных регионов России, на территории которого сосредоточены разнообразные рекреационные ресурсы и функционируют различные виды рекреационной деятельности. Разнообразные рекреационные ресурсы Кавказских Минеральных Вод вызывают интерес не только с хозяйственной точки зрения, актуально исследовать их и в историческом аспекте.

Материалы и методы: Исторический подход позволяет исследовать историю и особенности развития научных представлений о характере освоения климата как рекреационного ресурса Кавказских Минеральных Вод. Анализ исторических источников способствовал выявлению факторов изучения климата как рекреационного ресурса, и определить вклад отдельных

Результаты ученых в исследование климата региона.

исследования:

Обсуждение и заключения:

Ключевые слова:
Обобщены научные труды ученых и врачей, работающих в регионе Кавказские Минеральные Воды в конце XIX - начале XX в. Наряду с изучением гидроминеральных ресурсов в исследуемый период на Кавказских Минеральных Водах начинается активное исследование климатических условий с точки зрения использования их в лечебных целях. Проанализировано ряд научных работ, посвященных характеристике лечебного значения климата. Рассмотрены работы исследователей, занимающихся анализом влияния климата региона Кавказские Минеральные Воды или отдельных городов-курортов на организм человека. Показано значение работ членов Русского Бальнеологического Общества в исследовании климата как лечебного фактора, а также их вклад в развитие климатолечения на Кавказских Минеральных Водах.

B XIX в. в результате проведения метеорологических исследований появляются первые научные работы о климатических условиях Кавказских Минеральных Вод и климат региона приобретает большое значение в лечебных целях. Благодаря исследованиям климатических факторов курортного региона с 1910 г. Кисловодск как курорт начал функционировать и в зимний период.

Кавказские Минеральные Воды, климат, климатические условия, рекреационные ресурсы, курорт, Русское Бальнеологическое Общество. 
Zolnikova Yu. F. North-Caucasian Federal University, Stavropol, Russia

\section{THE STUDY OF THE CLIMATE OF THE CAUCASIAN MINERAL WATERS AS A RECREATIONAL RESOURCE IN THE LATE XIX-EARLY XX CENTURIES.}

\begin{abstract}
Introduction:
Caucasian Mineral Waters (KMV) - one of the oldest resort regions of Russia, on the territory of which are concentrated a variety of recreational resources and operate various types of recreational activities. A variety of recreational resources of Caucasian Mineral Waters are of interest not only from an economic point of view, it is important to explore them in the historical aspect.
\end{abstract}

Materials

and methods:

Research result:

Discussion and conclusions:

Key words:

The historical approach allows us to study the history and features of the development of scientific ideas about the nature of the development of climate as a recreational resource of Caucasian Mineral Waters. The analysis of historical sources contributed to the identification of factors in the study of climate as a recreational resource, and to determine the contribution of individual scientists to the study of climate in the region.

Summarized scientific works of scientists and doctors, working in the region Caucasian Mineral Waters in the late XIX - early XX centuries. Along with the study of hydromineral resources in the study period in the Caucasian Mineral Waters begins an active study of climatic conditions in terms of their use for medicinal purposes. A number of scientific works devoted to the characteristics of the therapeutic value of climate are analyzed. The work of researchers involved in the analysis of the influence of climate in the region of Caucasian Mineral Waters or individual resort cities on the human body. The importance of the works of members of the Russian Balneological Society in the study of climate as a therapeutic factor, as well as their contribution to the development of climate treatment in the Caucasian Mineral Waters.

In the XIX century, as a result of meteorological studies, the first scientific works on the climatic conditions of the Caucasian Mineral Waters appeared and the climate of the region acquired great importance for medicinal purposes. Due to researches of climatic factors of the resort region since 1910 Kislovodsk as the resort began to function and in the winter period.

Caucasian Mineral Waters, climate, climatic conditions, recreation resources, kurort, Russian Balneological Society.

\section{Введение}

Климатические факторы с лечебной и профилактической целью начали использовать еще в глубокой древности, когда солнце, воздух и вода широко применялись в целях укрепления здоровья. Но научное изучение вопросов климатолечения началось в Европе лишь с XIX в.

Климат курортного региона Кавказские Минеральные Воды (КМВ) отличается разнообразием. На формирование климата КМВ оказывают влияние следующие факторы: положение региона на юге страны, обеспечивающее большое поступление солнечной энергии; особенности циркуляции атмосфе- 
ры в южной части умеренных широт; рельеф и высота солнца над уровнем моря, создающие климатические различия в разных частях региона. Характер и изменчивость погоды на Кавказских Минеральных Водах определяется взаимодействием многих факторов формирования климата. Большое значение имеет происхождение и характер воздушных масс, локализация и перемещение барических систем и атмосферных фронтов, их структура, размер, изменение во времени и по пути перемещения в сложных орографических условиях, которые определяют характер погоды в различных городах-курортах Кавказских Минеральных Вод [9]. В Пятигорске лето теплое, зима умеренно мягкая. Кисловодск известен как зимний климатический курорт, на территории которого благодаря господствующим зимой воздушным массам и замкнутым условиям котловины наблюдается ясная сухая погода. Климат Железноводска соответствует горно-лесному и умеренно сухому климату среднегорий Альп. Климат Ессентуков отличается контрастностью - лето здесь жаркое и сухое, а зима морозная и дождливая.

Воздух в городах-курортах Кавказских Минеральных Вод характеризуется прозрачностью, высокой естественной ионизацией при низком коэффициенте униполярности ионов. Эти условия в совокупности с благоприятным режимом солнечного излучения позволяют проводить на КМВ все виды климатолечения. А курортные парки городов-курортов Кавказских Минеральных Вод очищают воздух от загрязнения и обогащают целебными летучими фитоорганическими веществами.

Лечебное действие климата Кавказских Минеральных Вод отмечалось еще в первые годы формирования курортов региона. На курортах КМВ неорганизованное, стихийное использование климатических факторов началось с первых лет существования этих курортов. Одной из форм климатолечения было пребывание лечащихся на свежем воздухе. Живя в кибитках и палатках, больные большую часть времени проводили на воздухе.

\section{Материалы и методы исследования}

В качестве источников использовались и анализировались научные труды и монографии исследователей Кавказских Минеральных Вод XIX - начала XX в.: Ф.А. Баталина, С.А. Смирнова, А.И. Воейкова, И.О. Зарубина и др., внесших большой вклад в изучение климата региона Кавказские Минеральные Воды как рекреационного ресурса. Изучены Протоколы и Записки Русского Бальнеологического Общества (РБО), в которых отражены результаты изучения климата Кавказских Минеральных Вод членами РБО, а также приводятся сведения об основах климатолечения в регионе. В результате, на основе разнообразного историко-географического материала обобщен опыт, исследованы подходы и методики, применяемые отдельными исследователями, работающими на Кавказских Минеральных Водах на рубеже XIX$\mathrm{XX}$ вв. в исследовании климатических условий как рекреационного ресурса. 


\section{Результаты исследований и их обсуждение}

Климат Кавказских Минеральных Вод давно высоко оценен курортологами, успешно и широко используется в курортном регионе как лечебный фактор.

Почти с момента возникновения курорт Кисловодск был признан одной из лучших горноклиматических станций. Исследователи Кавказских Минеральных Вод, побывавшие в Кисловодске в период его возникновения, отмечали живительный воздух данной территории. В последствие появлялись и более серьезные характеристики климата, основанные на научных наблюдениях. В 1861 г. Ф. А. Баталин, описывая Кисловодск, утверждал, что «климат Кисловодска - один из самых приятных и здоровых на Кавказе... Воздух чисто горный, легкий.., им дышится как-то легко...» [1]. Основной формой климатолечения в тот период являлось нахождение больных на свежем воздухе. Длительному пребыванию на воздухе способствовали хороший климат и благоприятные погодные условия теплого периода года.

Уже в 1874 г. в отчете по управлению Кавказскими Минеральными Водами отмечалось, что для изучения климатических условий в Пятигорске, Железноводске и Кисловодске были построены правильные метеорологические станции. Из Пятигорска в Тифлисскую обсерваторию посылались ежедневные телеграммы и ежемесячные отчеты о барометрических и термометрических изменениях атмосферы. Такие же наблюдения проводились в Кисловодске и Железноводске. В Ессентуках, из-за нехватки необходимых инструментов, наблюдались только температура воздуха и направление ветра [7].

В конце XIX в. появились первые научные работы, посвященные характеристике климатических условий отдельных местностей Северного Кавказа, в том числе и региона Кавказских Минеральных Вод. Так, работа директора КМВ С. А. Смирнова «Климат Пятигорска» (1869), была посвящена характеристике климата курорта с учетом его физико-географических условий, а также анализу влияния климата Пятигорска на организм человека [4].

В 70-80-е гг. XIX в. признается лечебное значение климата Кисловодского курорта. Этой проблему затрагивали ряд работ (Погожев, 1873; Зарубин, 1879; Склотовский, 1873 и др.) [7, 10, 12]. В 1873 г. П. Погожев на основе проведенных им наблюдений на метеорологической станции, сделал вывод, что климат Кисловодска имеет важное лечебное значение. Исследователь подчеркнул, что воздух Кисловодска возбуждал активную деятельность легких [10]

Большой вклад в научное исследование климата Кавказских Минеральных Вод внесли члены Русского Бальнеологического Общества. Значительная часть исследований обсуждалась на заседаниях РБО. Так, на заседании Русского Бальнеологического Общества в 1874 г., В.А. Георгиевский сделал доклад на тему «Перечень метеорологических наблюдений в Пятигорске за последние 5 лет» на основе авторских исследований. В 1891 г. Ф.И. Пастернацкий в докладе на заседании Русского Бальнеологического Общества отме- 
тил, что природные свойства Кисловодска как горной местности, обладающей живительным воздухом, создали курорту славу для прекрасного дачного местопребывания здоровых людей и полезное для больных [8].

Доклады о климатических особенностях Кисловодского курорта были сделаны также на заседании Русского Бальнеологического Общества в 1898 г. на темы «Кисловодск как курорт для сердечных больных» (В. И. Подановский и Н.И. Попов) и «О значении Кисловодска, как зимней горной климатолечебной станции» (П.И. Склотовский и В.Д. Спицын) [5].

Доктор П.И. Склотовский, постоянно живущий в Кисловодске, считал, что курорт пригоден для пребывания больных в более поздние осенние и зимние месяцы. Такие результаты им были сделаны на основе метеорологических данных, на собственных наблюдениях над больными, зимовавшими в Кисловодске и на изучении заболеваемости малярией местного населения. П.И. Склотовский отмечал, что зимние месяцы в Кисловодске выгодно отличаются от других курортов обилием солнца, малым количеством осадком и отсутствием ветра [5].

На основе метеорологических наблюдений, врачом был сделан вывод, что Кисловодск по своим климатическим условиям может в течение 9-10 месяцев - с 1 июля по 1 апреля или 1 мая - служить при надлежащих предосторожностях, местом непрерывного пребывания больных. В докладе отмечалась благоприятность климатических условий Кисловодска, но вместе с тем говорилось, что условия не настолько идеальны, что можно пренебречь всеми прочими факторами. В частности, для пребывания больных в зимнее время на курорте нужны приспособления (квартиры), необходим санитарный надзор для обеспечения чистоты воздуха и почвы. Но все эти указанные условия на курорте пока отсутствуют. Поэтому в настоящее время только очень ограниченное число больных может найти в Кисловодске сносные зимние помещения [5]. По результатам исследования авторы доклада рекомендовали построить в Кисловодске санаторий, который послужил бы ядром для будущей климатической станции. Причем в докладе отмечалось, что для устройства санатория не может служить первый попавшийся дом. Необходимо новое знание, расположенное на возвышенности, правильно ориентированное по сторонам света, специально приспособленное для быстрой дезинфекции, с защитными галереями для лечения воздухом и собственным парком. Для постройки санатория была рекомендована местность около «Красных камней».

Доклад П. И. Склотовского «О значении Кисловодска, как зимней горной климатолечебной станции» Русское Бальнеологическое Общество рекомендовало для обсуждения на первом Всероссийском съезде деятелей по климатологии, гидрологии и бальнеологии [4]. На обсуждение на съезде членами Русского Бальнеологического Общества были предложены следующие положения доклада: 
1. Характеристика климатических условий Кисловодска для непрерывного пребывания больных на курорте;

2. Постановка проблем по существующим в настоящее время бытовым и санитарным условиям Кисловодска для осеннего и зимнего пребывания больных на курорте;

3. Предложения по постройке в Кисловодске санатория с лечебным парком на возвышенном месте и вне жилого района для легочных больных.

В сентябре 1899 г. на заседании Русского Бальнеологического Общества П. И. Склотовским был сделан доклад на тему «Количество солнечных часов в Кисловодске с 6 августа 1898 г. по 6 августа 1899 г.» [13]. В данном исследовании врачом проводился подсчет числа солнечных часов на курорте в течение календарного года. В результате максимальное количество солнечных часов в Кисловодске составило 14,5 часов, а минимальное - 8 (при продолжительности летнего дня по календарю в 17 часов). Количество солнечных часов в год составило 2640 часов. По месяцам данные распределялось следующим образом:

$$
\begin{aligned}
& \text { февраль - } 122 \text { часа } \\
& \text { декабрь - } 152 \text { часа } \\
& \text { январь - } 163 \text { часа } \\
& \text { март - } 208 \text { часов } \\
& \text { ноябрь - } 216 \text { часов } \\
& \text { октябрь - } 218 \text { часов } \\
& \text { август - } 232 \text { часа } \\
& \text { сентябрь - } 238 \text { часов } \\
& \text { июль - } 244 \text { часа } \\
& \text { май - } 251 \text { час } \\
& \text { июнь - } 257 \text { часов } \\
& \text { апрель - } 339 \text { часов. }
\end{aligned}
$$

По временам года выявлены следующие данные:

$$
\begin{aligned}
& \text { весна }-798 \text { часов } \\
& \text { лето }-731 \text { час } \\
& \text { осень }-674 \text { часа } \\
& \text { зима }-437 \text { часов. }
\end{aligned}
$$

Наибольшее количество солнечных дней было зафиксировано в октябре и составило 22 дня, в том числе 18 дней подряд. За октябрем следует ноябрь - 21 солнечный день и 18 подряд, далее сентябрь - 16 дней и 13 подряд, а затем декабрь - 14 и 12 и январь - 14 дней с перерывами [13]. Наименьшее число солнечных дней пришлось на февраль и равнялось 6, что совпадает с 
наименьшим количеством солнечных часов. Наибольшее количество солнечных дней не совпало с наибольшим количеством солнечных часов в месяц. Максимальное количество дней зафиксировано в октябре и ноябре, а часов в апреле и июне, что объясняется высотой стояния солнца, то есть длиною дня в эти месяцы.

В течение 191 дня солнце светило не менее 8 часов, а в течение 150 дней солнце светило почти весь день.

Автор отмечает, что если допустить маловероятное явление, что наблюдаемый год самый солнечный из 27 лет прожитых им в Кисловодске, то и тогда Кисловодск будет занимать середину между средней Италией и центральной Испанией, где солнце светит 2000-3000 часов в год [13].

И. П. Склотовский насчитал 27 дней, в течение которых солнце или вовсе не показывалось или проглядывало на время менее часа, а также выявил, что никогда более двух дней подряд Кисловодск не оставался вовсе без солнца. Это обилие солнца одна из самых привлекательных сторон Кисловодска.

Обилие солнца, при других благоприятных климатических условиях отсутствие жары летом и значительного холода зимой, отсутствие туманов, сильных и частых ветров, - высокий аргумент в пользу Кисловодска, как климатического лечебного места.

В начале XX в. руководством Кавказских Минеральных Вод был поставлен вопрос о значении Кисловодска как климатического курорта. В этот период были изучены и подробно описаны климатические условия Кисловодска в зимнее время А.И. Воейковым. В 1910 г. ученым было дано заключение о том, что Кисловодск, благодаря обилию солнечных дней, отсутствию сильных ветров, большой редкости ненастья, небольшому количеству осадков и чистому горному воздуху может стать одной из лучших климатических станций. А.И. Воейков отметил, что на пространстве Европейской России Кисловодск - это единственное место с очень солнечным зимним климатом и выгодным транспортно-географическим положением, куда можно доехать по железной дороге [3]. В результате курорт Кисловодск стал приобретать славу климатического курорта не только в теплое время года, но и в холодное. С 1910 г. он начал функционировать круглогодично как горно-климатический курорт. Таким образом, Кисловодск стал не только местом для отдыха и последовательного лечения после лечения гидроминеральными ресурсами в Пятигорске и Ессентуках, но и курортом, на котором с большим успехом стало применяться климатолечение легочных и сердечных заболеваний. С 1 октября 1910 г. в Кисловодске был открыт зимний лечебный сезон. Численность отдыхающих в зимний сезон изменялась следующим образом: 1911 г. -600 чел., 1912 г. - 800 чел., 1913 г. - 1000 чел. [2].

На рубеже XIX-XX вв. в городах-курортах Кавказских Минеральных Вод появился и приобрел широкую популярность новый метод лечения - ис- 
пользование пересеченного рельефа. На курортах начали проводить лечение терренкуром - это лечение дозированными прогулками по пересеченной местности по системе Эртели. Правильно организованные прогулки по горам это средство, способное быстро восстанавливать здоровье. В таких прогулках сочетается несколько благоприятных для организма условий: высокое местоположение, чистый горный разреженный воздух, солнечный свет и др. Наличие таких условий было отмечено изначально в Железноводске [15]. Но постепенно такой способ лечения появляется и на других курортах региона Кавказских Минеральных Вод. Уже в 1910 г. терренкур в Железноводске имел 8 маршрутов, протяженностью более 10 км; почти 12 км маршрута терренкура было проложено в Кисловодске; были созданы маршруты терренкура в Пятигорске и Ессентуках.

\section{Выводы}

Благоприятные климатические условия Кавказских Минеральных Вод и их положительное лечебное влияние на организм человека отмечались местными жителями еще в древности. В XIX в. с возникновением городов-курортов Кавказских Минеральных Вод климат региона приобретает все больший интерес с лечебной точки зрения, появляются первые научные работы о климатических условиях КМВ в ходе проведения метеорологических исследований. С тех пор интерес к климату Кавказских Минеральных Вод постоянно возрастал. Благодаря исследованиям ряда ученых и врачей, работающих на Кавказских Минеральных Водах в конце XIX - начале XX вв. климатические условия региона приобрели большую известность, отдельные работы имели довольно глубокие сведения о климате КМВ, как рекреационном ресурсе.

Значительный вклад в научное изучение климата Кавказских Минеральных Вод как лечебного фактора внесло Русское Бальнеологическое Общество. Ряд работ членов РБО послужили толчком для последующих исследований климата региона и способствовали развитию климатолечения на Кавказских Минеральных Водах.

При изучении климата Кавказских Минеральных вод и отдельных городов-курортов ученые всегда в первую очередь выделяли Кисловодск, как город с большим количеством солнечных дней, в том числе в зимний период. Благодаря исследованиям климатических факторов С.А. Смирнова (1869), П.И. Погожева (1873), П. Склотовского (1889), А.И. Воейкова (1910) в 1910 г. Кисловодск становится круглогодичным курортом. 


\section{Библиографических список}

1. Баталин Ф. А. Пятигорский край и Кавказские Минеральные Воды. СПб, 1861, ч. І-ІІ. 601с.

2. Владикавказская железная дорога и лечебные местности Кавказа. 2-е изд., перераб. Пятигорск, 1915. 55 с.

3. Воейков А.И. Климат Кисловодска в зимнее полугодие и сравнение его с другими климатолечебными местами. СПб., 1910. $35 \mathrm{c}$.

4. Всероссийский съезд деятелей по климатологии, гидрологии и бальнеологии. І-й 1898 (программа). СПб., 1898. 15 с.

5. Записки Русского Бальнеологического общества в Пятигорске. Т. І. №1, 3, 5-6. Пятигорск, 1898.

6. Зарубин И.О. В Кисловодске как в лечебном приюте для страдающих грудными болезнями // Сборник материалов для изучения Кавказских Минеральных Вод. СПб., 1873. Т. І. С. 255273.

7. Отчет по управлению Кавказскими Минеральными Водами 1871-1872. Тифрлис, 1874. 44 с.

8. Пастернацкий Ф.И. Кисловодск и его лечебные средства: Отчет группового врача за сезон 1890 г. СПб., 1891. 79 с.

9. Поволоцкая Н.П. Климато-курортологические особенности Кавказских Минеральных Вод // Проблемы использования рекреационных ресурсов на курортах Кавказских Минеральных Вод. М., 1986. C. 83-81.

10. Погожев П.И. Кисловодск и его источник Нарзан. СПб., 1873. $346 \mathrm{c}$.

11. Протоколы заседаний Русского Бальнеологического Общества в Пятигорске. XIV. Пятигорск, 1874.

12. Склотовский П. Кисловодск как место лечения слабогрудных// Сборник материалов для изучения Кавказских Минеральных Вод. СПб., 1873. Т. 1. С. 290-309.

13. Склотовский П.И. Количество солнечных часов в Кисловодске с 6 августа 1898 г. по 6 августа 1899 г.//Записки Русского Бальнеологического общества в Пятигорске. Т. ІІ. №3. Пятигорск, 1899.

14. Смирнов С. Климат Пятигорска//Сборник статистических сведений Ставропольской губернии. Ставрополь, 1869.

15. Терренкуры в Железноводске. Лечение систематическими восхождениями по системе Oertel,a. Пятигорск, 1910. 12 с.

\section{References}

1. Batalin F. A. Pyatigorsk region and the Caucasian Mineral Waters. St. Petersburg, 1861, part I-II. 601 p.

2. Vladikavkaz railway and therapeutic areas of the Caucasus. 2nd ed., pererab. Pyatigorsk, $1915.55 \mathrm{p}$.

3. Voejkov A.I. Kislovodsk Climate in the winter half-year and its comparison with other climatological places. SPb., 1910. $35 \mathrm{p}$.

4. The All-Russian Congress of figures in climatology, hydrology and balneology. The I-th 1898 (the program). SPb., 1898. $15 \mathrm{p}$. 
5. Notes of a Russian Balneological society in Pyatigorsk. T. I. No. 1, 3, 5-6. Pyatigorsk, 1898.

6. Zarubin I.O. In Kislovodsk as in a medical shelter for the suffering from thoracic diseases // Collection of materials for studying of the Caucasian Mineral Waters. SPb., 1873. T. I. P. 255-273.

7. Report on management of Caucasian Mineral Waters 1871-1872. Tiflis, 1874. $44 \mathrm{p}$.

8. Pasternatskij F.I. Kislovodsk and its therapeutic agents: report of the group doctor for the season 1890. St. Petersburg., 1891. $79 \mathrm{p}$.

9. Povolotskaja N.P. Climatic and balneological features of Caucasian Mineral Waters // Problems of recreational resources use in Caucasian Mineral Waters resorts. M., 1986. P. 83-81.

10. Pogozhev P.I. Kislovodsk and its source Narzan. SPb., 1873. 346 p.

11. Protocols of meetings Of the Russian Balneological Society in Pyatigorsk. XIV Pyatigorsk, 1874.

12. Sklotovskij P. Kislovodsk as the place of treatment of the weakchested//Collection of materials for the study of the Caucasian Mineral Waters. SPb., 1873. Vol.1. P. 290-309.

13. Sklotovskij P.I. The Number of Sunny hours in Kislovodsk on August 6, 18986 Aug 1899//Zapiski of the Russian Balneological society in Pyatigorsk. Vol. III. No. 3. Pyatigorsk, 1899.

14. Smirnov S. The Climate of Pyatigorsk // the Collection of statistical data of the Stavropol province. Stavropol, 1869.

15. Terrenkura in Zheleznovodsk. Treatment systematic climbing on the system of Oertel and. Pyatigorsk, 1910. 12 p.

Рукопись поступила в редакцию: 12.05.2018, принята к публикации 26.08.2018

\section{6 авторах}

Зольникова Юлия Федоровна, кандидат географических наук, доцент, доцент кафедры социально-экономической географрии, геоинформатики и туризма Северо-Кавказский федеральный университет, ул. Пушкина, 1, к. 2, ауд. 120, Тел. (928) 631-88-30. E-mail: zolnst@ mail.ru.

\section{About the authors}

Zolnikova Yuliya Fedorovna, candidate of geographical Sciences, associate Professor, associate Professor of the Department of socio-economic geography, Geoinformatics and tourism North Caucasus Federal University, Pushkin str., 1, building 2, AUD. 120, Tel. (928) 631-88-30. E-mail: zolnst@mail.ru. 